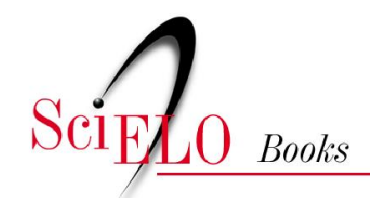

\title{
II - O desenvolvimento econômico recente na Amazônia e seus aspectos demográficos
}

\author{
Fernando Henrique Cardoso \\ Geraldo Müller
}

CARDOSO, FH., and MÜLLER, G. Amazônia: expansão do capitalismo [online]. Rio de Janeiro: Centro Edelstein de Pesquisas Sociais, 2008. pp. 29-39. O desenvolvimento econômico recente na Amazônia e seus aspectos demográficos. ISBN: 978-85-99662-73-1. Available from SciELO Books $<\underline{\text { http://books.scielo.org }>\text {. }}$

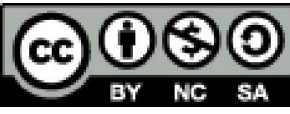

All the contents of this chapter, except where otherwise noted, is licensed under a Creative Commons Attribution-Non Commercial-ShareAlike 3.0 Unported.

Todo o conteúdo deste capítulo, exceto quando houver ressalva, é publicado sob a licença Creative Commons Atribuição Uso Não Comercial - Partilha nos Mesmos Termos 3.0 Não adaptada.

Todo el contenido de este capítulo, excepto donde se indique lo contrario, está bajo licencia de la licencia Creative Commons Reconocimento-NoComercial-CompartirIgual 3.0 Unported. 


\section{II - O desenvolvimento econômico recente na Amazônia e seus aspectos demográficos}

Podem-se distinguir duas fases na economia amazonense no período posterior a 1940: uma que vai desta data até 1945, caracterizada por um novo surto da borracha, e outra de 1945/50 em diante, caracterizada pelo desenvolvimento de alguns outros produtos voltados para o mercado; ambos os fenômenos possuem suas particularidades demográficas.

\section{Borracha, castanha, pecuária}

Com a entrada dos americanos na guerra, e com os japoneses controlando a situação no Oriente (Ceilão, Índia, Birmânia, Malásia, Indonésia), que era de onde provinha a maior parte da borracha natural consumida pelos aliados, os EUA decidem iniciar um programa de exploração da Hevea na América Latina.

Quanto ao Brasil: "Em 1941 se estimava em 34000 o número de seringueiras na região, produzindo 18233 toneladas de borracha. Para aumentar a produção anual para 45000 toneladas, seria necessário o dobro de seringueiras ou mais (...). Esses esforços (americano e do governo brasileiro) resultaram no deslocamento de 25000 trabalhadores para a região, que, juntamente com outros fatores, aumentaram a produção para 32300 toneladas em $1945 "$ ".

A "batalha da borracha" encontra novamente no nordeste a fonte de mão de obra; e mais uma vez, como ocorreu antes, como em 1877-80, uma severa e prolongada seca, a de 1942, atua como elemento de propulsão virtual. Desta situação resultou uma imigração basicamente familiar; e em que pesem os gastos elevados em transporte etc., essa espécie de imigração tinha o sentido claro de diminuir as chances de retorno, para garantir mão de obra.

Não se dispõe de dados sobre o quinquênio, uma vez que os dados censuais são de caráter decenal. Não obstante, pode-se ponderar, com base

\footnotetext{
${ }^{39}$ Todas as informações dessa fase estão em A Borracha da Amazônia e a II Guerra Mundial, de CORRÊA, Luiz de Miranda, Manaus, Ed. Governo do Estado do Amazonas, 1967; consulte-se principalmente o Cap. "Seringueiros para a Amazônia".
}

em Graham e Buarque ${ }^{40}$, que entre 1940-50, a Região norte foi acima de tudo uma área de emigração; esta alcançou quase 50 mil. No entanto, o então Território do Acre apresentou um saldo migratório positivo, algo semelhante a 6500 pessoas, o que certamente está a indicar o local de adensamento dos imigrantes à época da guerra. Como "o Acre é um imenso seringal" este adensamento de população indica uma "resposta" ao aumento dos preços da borracha. ${ }^{41}$

A segunda fase desses últimos 30 anos caracteriza-se pela diversificação do panorama da região, através de outras atividades mercantis. Os acréscimos populacionais após 1940 - a população passa de 1440 mil naquele ano para 3 milhões e meio em 1970, sendo que na última década o saldo migratório ultrapassa 67 mil pessoas - não mais são explicáveis pela produção da borracha, que a partir de 45 mantém-se em torno de 32 mil t anuais. Pode-se dizer que tais acréscimos se desvincularam da extração do látex, ligando-se a outros produtos suscitados pelo mercado mundial (minérios), ou pelo mercado nacional regional (juta, pimenta-do-reino, malva, arroz, pecuária, petróleo, castanha, algodão, mamona).

Como se vê, a partir de então surgem novas culturas comerciais, desenvolve-se uma pecuária essencialmente de cunho extensivo, criam-se empreendimentos minerais de grande porte, intensifica-se a extração da castanha (que se combina com a pecuária e a agricultura) etc. Vejamos com mais detalhes o desenvolvimento dessa situação nova no setor extrativo florestal (borracha - castanha).

A produção da borracha mantém-se, a partir de 1945, como já frisamos, praticamente estagnada, girando ao redor de 32 mil t por ano. Em termos de participação no produto bruto da agricultura, nas unidades da Região norte, a borracha, em 1959, possuía ainda significado em Rondônia $(77 \%)$ e no Acre $(70 \%)$. "A borracha perdeu a liderança das atividades econômicas na Amazônia porque o extrativismo expedicionário deixou de ser atividade de rentabilidade compensadora... O processo de trabalho...

${ }^{40}$ Apud. Redistribuição Regional etc., op. cit.

${ }^{41}$ Que a "batalha da borracha" levou muita gente ao Acre é fato incontestável; já a relação entre saldo migratório decenal positivo e aumento dos preços da borracha não é mais tão direta como o foi durante o ciclo da borracha; no período $1948-50$ os preços aumentaram $28 \%$, no de $1951-54,30 \%$, no período $195-4-56,44 \%$, ao passo que o Acre, entre 1950-60, acusa um movimento emigratório. Ver Graham e Buarque, op. cit., e BASA, p. 206. 
continua primitivo, arcaico". ${ }^{42}$ De fato, o seringalista, proprietário do seringal ${ }^{43}$ é sobretudo um comerciante que mantém na sede um armazém, onde "compra" (de fato, o seringueiro apenas entrega o produto ao seringalista) a borracha produzida pelos seringueiros e lhes vende charque, sal, pólvora, armas etc.; este armazém é o nódulo inicial da já mencionada cadeia do sistema de aviamento. $\mathrm{O}$ seringueiro, sobretudo nas fases de queda do preço da borracha, faz pequenos roçados de mandioca, milho e feijão; no entanto, nem sempre o roçado the é permitido. De qualquer modo, sendo o seringueiro empregado ou posseiro, basta um aumento dos preços da borracha para a mão de obra dirigir-se para a extração do látex; isso ocorre até mesmo no Acre, onde os roçados são frequentes.

Nessa breve descrição do modo de vida desses produtores não podemos esquecer que os seringueiros, e isto é comum onde as condições naturais o permitem (Pará, área sudoeste mais a área contígua do Amazonas), dedicam-se à coleta da castanha na época chuvosa ou na entressafra da borracha; no entanto, não há possibilidade de eles se empregarem nos jutais, dada a coincidência das safras.

Com a economia extrativa da castanha-do-pará parece terem ocorrido modificações importantes. A alteração legal no estatuto do arrendamento de terras devolutas, em 1954, na observação de Otávio Velho "assegura o direito de renovação" do arrendamento ao Estado, graças ao que uma série de melhorias, como estradas, barracos e roçados nos castanhais tornava-se viável; com o aumento da produtividade, a demanda de mão de obra caiu de até $50 \%$, cessando a migração temporária do Baixo Tocantins (PA) e oeste maranhense. ${ }^{44}$ Essas melhorias devem haver-se restringido, entretanto, a certas propriedades pois, como consta em BASA, "a coleta dos ouriços e a extração de suas sementes é feita pelos processos mais primitivos" ${ }^{45}$

\footnotetext{
${ }^{4}$ BASA, p. 198. Isso é confirmado por Manuel Correia de Andrade em Paisagens $e$ Problemas do Brasil, Ed. Brasiliense, São Paulo, 1968.

${ }^{43}$ Grande propriedade com sede à margem de um rio com milhares de hectares e de limites imprecisos. Ainda hoje, apenas em Rondônia, seringueiros e seringalistas detêm 400 mil ha de terra não titulados.

${ }^{44}$ Lei Estadual $n^{\circ} .913$, de 1954; sobre essa lei e a respeito das frentes agrícola, pecuária, mineradora e extrativa localizadas no Pará, consulte-se Otávio Velho: Frentes de Expansão e Estrutura Agrária, op. cit. Boa parte das informações no presente estudo sobre essas frentes foi extraída dessa obra.

${ }^{45}$ BASA, op. cit., p. 149
}

Há um aspecto neste processo que merece ser ressaltado: o emprego da mão de obra da área em mais de uma atividade, geralmente agroextrativa, quando não também em atividades pecuárias. ${ }^{46}$ Tudo leva a crer que a um trabalho mercantil alia-se o trabalho para sustento próprio, principalmente nas áreas extrativas não borracheiras mas até mesmo nessas últimas.

Por outro lado, com o aumento da demanda urbana regional e com as possibilidades de crédito e transporte, ocorreram uma expansão e até mesmo certas melhorias na qualidade da pecuária. Esboça-se uma tendência que é a de substituir o castanhal por pastagens. Otávio Velho afirma que o lucro com a castanha foi, em boa parte, investido na pecuária; além disso, ela desenvolveu-se também graças à utilização de empréstimos bancários fornecidos para a racionalização dos castanhais que são desviados para a pecuária. ${ }^{47}$ Não obstante, a tendência à melhoria do gado foi quase exceção frente ao modo extensivo de sua exploração.

\section{Pimenta-do-reino e juta}

Por outro lado, se a propriedade dos seringais, castanhais e do rebanho encontra-se em poucas mãos, o mesmo não acontece na área da juta e da pimenta-do-reino. Nestes cultivos predomina a pequena propriedade, constituindo-se assim outro elemento de diversificação do panorama da Amazônia. Entre os dois produtos há, entretanto, uma distinção socioeconômico-demográfica importantíssima: a juta integra-se no esquema geral do aviamento e dela dependem umas 200 mil pessoas enquanto que a pimenta-do-reino opera em um esquema cooperativado, não implicando em sua produção mais do que 2000 pessoas.

\footnotetext{
${ }^{46} \mathrm{Na}$ área de Imperatriz, centro do triângulo formado pelas cidades de Bacabal e Carolina (no MA) e Marabá (no PA), encontramos a associação roçado e algodão-babaçu; vide VALVERDE, Orlando e DIAS, Catharina V., A Rodovia Belém-Brasília, Rio de Janeiro, IBGE, 1967; no vale do Mearim (MA) roçado-arroz e babaçu: vide MEDINA, Carlos A., Mão de obra em RN. PE, BA, MA e PI, 1958 (mimeo.).

${ }^{47}$ Significativa vitalização econômica e demográfica conheceu a área de Imperatriz com a abertura da Rodovia Belém-Brasília. Ao norte desta cidade surgiu uma zona de invernadas onde a pecuária conta com pastos plantados, propriedades cercadas, melhoria da espécie bovina, com a introdução do zebu. Consultem-se: Microrregião Homogênea e a Divisão do Brasil, IBGE, 1968, e VALVERDE, Orlando e DIAS, Catharina V., op. cit.
} 
A pimenta é produzida na área bragantina, entre Belém e Bragança; concentra-se, no entanto, em Tomé-Açu, município da área guajarina. A juta é cultivada nas largas várzeas do médio vale do rio Amazonas, entre Santarém (PA) e Manacapuru (AM). Ambas as culturas foram introduzidas pelos japoneses na década de 30; alcançarão expressão econômica na fase atual.

Se em 1941 a produção da juta é de 1100 t, em 1960 alcança 39 mil e em 1964, 51 mil t. Para esse aumento devem ter concorrido o aumento da demanda nacional (sacaria), a proibição federal de sua importação (já em 1947) e a participação de capitalistas de Belém e São Paulo interessados na produção.

A maioria dos produtores são pequenos proprietários que plantam em suas terras ou em terras arrendadas. As glebas são, de fato, diminutos lotes de terra $-0,5$ a 2,0 ha. Geralmente o aumento da produção acha-se vinculado ao aumento da área cultivada, o que implica subtrair terra às matas, levando os juticultores às terras firmes, terras mais altas. A partir de 1962 - considerados a demanda urbana de carne, a valorização das terras limpas e com pastos, o peso menor do trabalho na pecuária contraposto ao estafante trabalho exigido na plantação de juta que se soma ao esquema de endividamento com o aviador - surge uma tendência para, aos poucos, passar da juta à pecuária de corte. ${ }^{48}$

Atualmente os produtores não são mais só os japoneses; há também brasileiros, sendo que alguns japoneses passaram a ser aviadores desses últimos. O sistema de aviamento ao nível da produção e primeiro patamar da comercialização é intricado, pois um produtor pode ser também um pequeno aviador. Pode ser um dono de venda ou de um armazém local que avia os pequenos produtores. A partir daí ocorre o afunilamento: um comerciante de um núcleo maior avia vários donos de venda... até alcançar as grandes casas aviadoras de Manaus e Belém. Eis um exemplo da sensibilidade dessa população aos preços de mercado, tópico abordado no capítulo anterior. Com o aumento da demanda nacional, capitalistas sulinos, através daquelas duas praças, reanimam o mecanismo de aviamento. A possibilidade de ganhos monetários levou, em pouco tempo, milhares de famílias à coleta e produção $0^{49}$ da fibra sob o controle do capital comercial, induzido ao

\footnotetext{
${ }^{48}$ PIAZZA, Paulo Della, Santarém, 1962, mimeo.

49 Ainda é, basicamente, uma atividade extrativa, mas que, aos poucos, recebe elementos técnicos que permitem organizar a produção. Tais elementos são fornecidos pela escola agrícola de Vila Batista, no município de Paratins.
}

empreendimento pelo capital industrial. De fato, o que alimenta o aviamento são os empréstimos bancários feitos aos comerciantes, em boa medida pela rede bancária pública. Ao nível produtivo, o trabalho repousa em base familiar. "O produtor de juta vive isoladamente, em condições precárias, sem a mínima assistência médico-hospitalar e educacional, dedicando-se a um empreendimento árduo. Se a juticultura ainda apresenta algum resultado, este é função da utilização da força de trabalho familiar - mulher e filhos -, estes quase sempre menores. E esse resultado é absorvido pelo sistema de aviamento. Concorre para a sustentação desse sistema espoliador o fato de os financiamentos serem feitos aos comerciantes e não ao produtor". ${ }^{50}$

Curiosamente, essa mesma fonte afirma que "o mais importante obstáculo ao desenvolvimento da juticultura nessa região é a escassez de mão de obra", deixando de considerar a abundância do lucro comercial e industrial. A reiteração dos interesses da intermediação comercial e financeira ao âmbito regional bloqueia a aplicação produtiva na juticultura, do que resulta o esfalfamento da força de trabalho familiar. Jogar na escassez de mão de obra como "o mais importante obstáculo" é exigir a reprodução da forma de trabalho empregada, tornando imune o "sistema espoliador".

Em termos demográficos, tudo leva a crer que a juta criou um setor de atividade novo na Amazônia. Segundo Desenvolvimento Econômico da Amazônia, "a mão de obra empregada nesta produção é de cerca de 42 mil pessoas, o que representa $13 \%$ do pessoal ocupado na agricultura e pecuária da região. Estima-se que mais de 200 mil pessoas já dependem, diretamente, da cultura da juta" ${ }^{51}$. Tal estimativa mostra-se realista, em que pese a dificuldade de uma avaliação mais precisa. Se levarmos em consideração a população da Microrregião 10 (AM) e da Microrregião 12 (PA) (ver mapa anexo), que soma 722 mil pessoas e dela subtrairmos aquela lotada nas cidades de Manaus e Santarém, resultará algo semelhante a meio milhão de pessoas localizadas no "meio rural" (há outros núcleos menores). Ora, o vale do médio Amazonas possui parte dessa última população vinculada ao extrativismo,balata (espécie de látex) e castanha, pecuária e rizicultura. Dessa feita, considerar que umas 300 mil pessoas

\footnotetext{
${ }^{50}$ BASA, op. cit., pp. 170-171.

${ }^{51}$ BASA, op. cit., p. 166. Os números são de 1960. 
dependem diretamente dessas atividades e, por conseguinte, 200 mil da juta, não parece ser uma hipótese descabida. ${ }^{52}$

Quanto à ocupação (emprego) da força de trabalho, a juta ocupa a família durante 180 a 200 dias. O resto do ano é empregado ou em um segundo plantio chamado "juta da larva" (150 dias) ou em cultura de subsistência ${ }^{53}$.

A pimenta-do-reino concentra-se na zona bragantina (municípios de Belém e Castanhal) e na Guajarina (município de Tomé-Açu). Neste último município a colonização obedeceu a planos prévios. Baseia-se em pequenas propriedades, 20 a 25 ha, com um forte sistema cooperativo que tem por esteio econômico um produto altamente valorizado no mercado mundial.

A cultura da pimenta-do-reino é uma lavoura permanente e exige elevadas somas em insumos; trata-se de um sistema de cultivo intensivo que emprega adubo orgânico adquirido no nordeste e adubos químicos importados do Japão, Estados Unidos e Alemanha Ocidental ${ }^{54}$. A colheita é manual, exigindo uma relativamente numerosa mão de obra, não só familiar como assalariada (com maioria de mulheres, mas também crianças e velhos participam) o que provoca êxodo sazonal da zona do Tocantins, do vale do Xingu, dos municípios de Cametá, Macajuba e Moji para Tomé-Açu. ${ }^{55}$

À medida que os negócios evoluem, o produtor adquire mais terras, melhora sua casa e passa a supervisionar os assalariados - dizem Orlando

\footnotetext{
${ }^{52}$ Se a produção aumenta em função da área cultivada e da massa de mão de obra, o aumento da primeira de 39 mil t em 1960 para 51 mil t em 1965, concomitante ao aumento da área cultivada de 28 mil ha para 42 mil, - é de sugerir, pois, que a mão de obra, nesse quinquênio, quase que dobrou.

53 BASA, op. cit., p. 170. "Aqui é assim: durante seis meses a gente só vive pra juta. Semeando, colhendo e plantando. O resto do ano? Bem, o resto do ano é pra pegar peixe, olhar pra água e esperar a vida. Não é trabalho pequeno, não, meu compadre, porque daqui a 10 anos já sou um velho imprestável (Raimundo tem 30 anos) pro mergulho. Mas não me queixo, não, porque na minha terra eu colhia borracha, e a seringa é que é trabalho de cão. É o dia inteiro no meio da selva, almoçando malária e jantando impaludismo. No fim, você não vê nada: nem dinheiro, nem terra, nem borracha, e nem nada”. BORBA, Marco A., Opinião, 5/12/75, nº 161.

${ }^{54}$ Sobre esse assunto consulte-se A Rodovia Belém-Brasília, obra citada. Dado o extremo cuidado requerido pelas várias fases do cultivo, a cultura da pimenta-do-reino foi chamada cultura de vasos por Dirceu Lino de Mattos em As Regiões Geoeconômicas, in Brasil: A Terra e o Homem, São Paulo, Cia. Editora Nacional/Ed. da USP, 1970, p. 447.

${ }^{55}$ Consulte-se PENTEADO, Antônio R., O Uso da Terra na Região Bragantina-Pará, Instituto de Estudos Brasileiros, USP, São Paulo, 1.967, Cap. 3, pp. 50-58.
}

Valverde e Catharina V. Dias. Não sabemos se os casos descritos pelos autores - de ascensão econômica etc. - representam uma tendência ou não. Em todo o caso, cabe apontar para as condições singulares de produção e comercialização do produto.

Todos os agricultores japoneses de Tomé-Açu são cooperativados. A cooperativa adquire a pimenta e a vende; o mesmo faz com outros produtos que eventualmente formam o excedente; por outro lado, adquire gêneros, insumos e máquinas (os produtores beneficiam a pimenta em suas propriedades), bem como fornece assistência médica. Ainda através da cooperativa, os agricultores recebem financiamentos do Banco do Brasil.

O BASA afirma que esse "cooperativismo é um exemplo eloquente de como se pode vencer o sistema tradicional de crédito e comercialização" ${ }^{\text {"56 }}$. Sem dúvida isso é verdade; contudo, deve-se situar esse feito como ocorrendo num contexto assaz específico: o produto em questão é de alta densidade econômica, houve ajuda financeira governamental ${ }^{57} \mathrm{e}$ ocorreu pequena expansão demográfica: em 1966 a colônia contava com 300 famílias, isto é, seguramente menos de 2 mil pessoas. A repercussão externa à colônia, em termos de assalariados, tende a cair, já que a mão de obra familiar é toda ela movimentada e, recentemente, vêm sendo utilizadas debulhadeiras mecânicas.

O Brasil concorre com cerca de $5 \%$ da produção mundial; a quase totalidade dessa produção de pimenta provém do Pará e, nele, de ToméAçu. De fato, das $8943 \mathrm{t}$ produzidas no Brasil, a Região norte participa com 8446, podemos dizer 95\%, toda ela do Pará; e a produtividade dos pimentais dessa região é bem superior à das outras áreas produtoras, pois enquanto o país todo cultivou 4426 ha para produzir 8,9 t, no Pará, podemos dizer, Tomé-Açu produziu 8,4 toneladas em 2104 ha. ${ }^{58} \mathrm{Em} 1969$ (somente dispomos de dados para o Brasil), o país produziu mais de $14 \mathrm{mil}$ t em 5,5 mil ha. ${ }^{59}$ Conservando-se as proporções de 1965, pode-se ter uma

${ }^{56}$ BASA, op. cit., p. 181.

${ }^{57}$ Por exemplo, a indenização para erradicar os pimentais contaminados em 1972. Consulte-se o Boletim do Banco do Brasil, Ano VII, 1971, no. 4, p. 21.

${ }^{58}$ Dados de Microrregiões Homogêneas, op. cit., e Anuário Estatístico do Brasil, IBGE, 1967, p.101.

${ }_{59}$ Anuário Estatístico do Brasil, IBGE, 1973, p. 179. 
ideia da evolução do produto na Colônia Agrícola de Tomé-Açu - cuja repercussão na demanda de mão de obra tende a cair em termos relativos.

\section{Outros produtos e processos em curso}

Além das atividades extrativas, agrícolas e pecuárias descritas, "recentemente, um novo produto - o manganês - é ativamente explorado no Amapá, cujo território vem obtendo alguns benefícios de sua exploração. A existência de petróleo foi reconhecida em mais de um ponto da região e as sondagens continuam a ser feitas (...) A atividade industrial começa a adquirir alguma importância local em Belém e Manaus. Nesta última já funciona uma refinaria de petróleo que trabalha com o produto oriundo dos campos de Ganzo Azul, no Peru. Na região de Belém, ao lado de algumas indústrias antigas, estão surgindo novas fábricas, construí das dentro das mais rigorosas exigências técnicas (indústrias de aniagem, vidros, bebidas etc.)" ${ }^{60}$

Sucintamente podemos afirmar que o panorama mais recente, 1967/70 em diante, está marcado sobremaneira pelas políticas do Governo Federal; internamente a repercussão maior está recaindo sobre a terra; disputam-se a legitimidade das posses, a legitimidade de certas propriedades e, nesse processo estão, de um lado, grandes empresas do sul e internacionais, incentivadas pelo governo, desejosas de centenas de milhares de ha e, de outro, as tentativas do INCRA de organizar a frente de pequenos e médios proprietários e posseiros que desordenadamente vão entrando na região, bem como criar núcleos, formando colônias de povoamento, como se analisará nos Capítulos VIII, IX e X.

Os interesses das grandes empresas estão voltados para a mineração (estanho, bauxita e ouro em Rondônia, manganês no Amapá), extração e beneficiamento dos diversos tipos de madeira, pecuária de corte e rizicultura, soja e cana-de-açúcar ${ }^{61}$. A tendência governamental é de apoio a

\footnotetext{
${ }^{60}$ MATTOS, D. Lino de, op. cit., p. 445.

${ }^{61}$ Cinco grupos, nacionais e estrangeiros, dividem entre si a "Província Estanífera" que vai do Pará às terras bolivianas; se bem que as 4 mil $\mathrm{t}$ anuais de cassiterita representem apenas algo cerca de 3 ou $4 \%$ da produção mundial, os depósitos permitem aumentos significativos. A partir de 1971 as lavras foram mecanizadas e o "Governo fechou os garimpos e removeu os garimpeiros da Região". No Amapá a ICOMI, criada com a associação da Bethlehem Steel (EUA) com o grupo Azevedo Antunes, que agora conta também com a Brumosa, ao explorar o manganês (em 1965, 953 mil t) alterou a feição do Território. Nos limites dessa Unidade da
}

grandes projetos, tendo em vista acelerar o processo de ocupação efetiva da Amazônia. ${ }^{62}$

Em resumo, pode-se dizer que do império dos aviadores e seringalistas do ciclo da borracha passa-se, atualmente desde os anos 60, com a abertura das estradas, o que ocasionou a elevação do preço das terras e, notavelmente, desde os primeiros anos 70, com a decidida política governamental de penetração na Amazônia -, para o império dos grandes grupos econômicos do centro-sul brasileiro juntamente com grupos estrangeiros, numa verdadeira repetição ampliada e atualizada do papel desempenhado pela terra e pelos homens que nela trabalharam durante a época da "mais criminosa organização do trabalho que ainda engenhou o mais desacirrado egoísmo", na opinião de Euclides da Cunha em À Margem da História. ${ }^{63}$

Sem nos adiantarmos ao que será analisado nos Capítulos VI e seguintes, referente aos mecanismos atuais de integração da Amazônia ao movimento geral do capital nucleado no sul, é suficiente, por enquanto, registrar a aurora desse novo devassamento.

O Estado de São Paulo de 2/11/1975 assim concluía seu editorial que dava início à publicação de nove artigos sobre a Amazônia: "Após 10 anos, os resultados da política de colonização são desoladores, senão para os colonizadores dotados de maiores recursos, pelo menos para a grande maioria das pessoas envolvidas nesse processo: os camponeses expulsos de suas terras de origem e os nativos da Amazônia, virtualmente transformados em colonizados".

Os "camponeses", garimpeiros, seringueiros, lenhadores, sitiantes etc. desempenharam seu papel: levaram para os confins amazônicos a população exigida pelas atividades mercantis atualmente em implantação,

Federação com o Pará, "o milionário americano Daniel K. Ludwig planta o maior arrozal do mundo, numa área de 1,5 milhões de hectares, de acordo com as últimas lições de tecnologia": - Informação de Visão, 07/10/1974, pp. 25 a 38. No Maranhão implanta-se a siderúrgica de Itaqui (subúrbio da Capital maranhense). "A usina de Itaqui receberá minério de ferro do Pará, da serra dos Carajás, com teor de 69,5\%, e cujas reservas são calculadas em 18 bilhões de toneladas," Visão, 04/11/1974, p.80.

${ }^{62}$ Com esse objetivo expresso foi criado o Programa de Pólos de Desenvolvimento Agropecuários e Agrominerais da Amazônia (Polamazônia), outubro de 1974

${ }^{63}$ CUNHA, E. da, À Margem da História, Porto, Lello e Santos, 1909, apud Prado e Capelato, op. cit., p. 298 
dos empresários nacionais e estrangeiros; mostraram a possibilidade de se viver naqueles confins: passaram facão, foice, machado, plantaram, colheram e se aclimataram. Foi o devassamento das frentes pioneiras. Limpo o terreno, a história muda: de colonizadores passam a colonizados. Convencidos pela violência, servem ao novo devassamento. A violência, para espanto dos estudiosos de encomenda, é aqui uma potência econômica, pois abre caminho ao desenvolvimento, à acumulação. “... o pioneirismo em Rondônia apresentou nos últimos cinco anos alguns dos mais dramáticos capítulos da história da corrida para o norte desencadeada pelo governo uma história contada por milhares de mortes, violência, total desrespeito às leis, destruição do meio ambiente, agressões à população nativa, desmandos administrativos, prepotência, corrupção, crimes de toda a espécie" ${ }^{\circ 4}$.

Dessa maneira, tendo a violência por parteira, o capital ingressa na produção agropecuária e mineira amazônica; passa-se para uma nova etapa histórica em que a Amazônia não apenas serve à acumulação "externa" mas passa a viver, também, internamente, para ela.

${ }^{64}$ O Estado de S. Paulo, 5/11/75. Os nativos, que "eram mais de um milhão quando o primeiro colonizador pôs os pés em terra amazônica, hoje podem ser até 60 ou 70 mil, não mais que isso". Idem, 12/11/75. Veja-se, também, RIBEIRO, Darcy, op. cit., Parte Três, Cap. XII. 